\title{
Bartolomeu de Las Casas e o novo mundo
}

\section{Bartolomeu de Las Casas and the new world}

\author{
Fernando Cardoso Bertoldo*
}

Recebido: 27/12/2018. Aprovado: 12/04/2019.

Resumo: Esta pesquisa é uma breve reflexão sobre o pensamento do Frei Bartolomeu de Las Casas (1474-1566) acerca da conquista da América e sua defesa em favor dos povos indígenas. A partir da leitura da obra "Único modo de atrair todos os povos à verdadeira religião", buscam-se elementos para compreender a vida, obra e trajetória deste defensor dos povos nativos da América Hispânica. Faz-se um confronto entre Las Casas e Juan Ginés de Sepúlveda, os quais entram em contradição sobre a questão da colonização e conquista espanhola. Las Casas fará uma crítica severa ao sistema de encomenda como forma de protesto e adesão a proposta da defesa dos indígenas.

Palavras chave: Evangelização. Bartolomeu de Las Casas. Juan Ginés de Sepúlveda.

\begin{abstract}
This research is a brief reflection on the thought of the Fray Bartolomé de Las Casas (1474-1566) about the conquest of America and its advocacy on behalf of indigenous peoples. From the reading of the work "One way to attract all people to the true religion", elements seek to understand the life, work and career of this great defender of the native peoples of Hispanic America. There is a confrontation between Las Casas and Juan Ginés de Sepúlveda, which, come into conflict on the question of colonization and the Spanish conquest. Las Casas will make a big criticism of the encomienda system. Bartholomew waive his encomienda to protest and support the proposal of the defense of indigenous people.
\end{abstract}

Keywords: Evangelization. Bartolome de Las Casas. Juan Ginés de Sepúlveda.

\section{Introdução}

Frei Bartolomeu de Las Casas tornou-se defensor dos indígenas no novo mundo do século XVI. Defendia um processo de colonização pacífica das Américas e considerava os indígenas filhos especiais de Deus

* Doutorando em Teologia (EST, São Leopoldo, RS). Mestre em Teologia (PUC-RS, Porto Alegre, 2017). Graduado em Psicologia (PUC-RS, Porto Alegre, 2013).

E-mail: nandobertoldo@hotmail.com. 
que deveriam ser protegidos. Segundo Las Casas, a religião não pode estar ligada à guerra. A pergunta que permeia toda ação evangelizadora de Las Casas é: qual o método de aplicar o Evangelho no contexto da conquista?

Las Casas defendia a dignidade dos índios e sua dignidade humana contra posturas que visavam reduzi-los a escravos, passíveis de serem agredidos em sua humanidade, cultura, sociedade e religião, evocando o conceito dos direitos humanos (derechos humanos) ${ }^{1}$ na obra "Tratado sobre la materia de los indios que se han hecho esclavos". ${ }^{2}$ Ele defendeu o princípio de que a fé não pode ser imposta, pois está além da compreensão racional. A fé, na compreensão de Las Casas, é algo bom, e que conduz à salvação, devendo ser incutida nos indígenas pela Igreja, de forma delicada suave e doce. ${ }^{3}$

A partir da leitura da obra "Único modo de atrair todos os povos à verdadeira religião", esta pesquisa busca compreender a vida, obra e trajetória de Bartolomeu de Las Casas, defensor dos povos nativos da América Latina, em oposição a Juan Ginés de Sepúlveda sobre a questão da colonização e conquista espanhola. Compreende-se que Bartolomeu de Las Casas defendeu o respeito à dignidade do objeto da evangelização.

\section{Contexto Histórico em que viveu e atuou Frei Bartolomeu de Las Casas}

A América esteve isolada do resto do mundo durante milênios. Nessa condição, desenvolveu sociedades as mais variadas, desde estados bem estruturados até chefaturas mais ou menos estáveis de tribos nômades e seminômades. Esse mundo sofreu um brutal golpe com a invasão dos europeus no final do século XV e início do XVI, em um encontro de civilizações que trouxe consequências nefastas para as sociedades ameríndias. A resposta à invasão foi igualmente variada: alguns, por meio de alianças, aceitando a nova condição política e social que se impunha;

1 SINNER, Rudolf von. Theologie in Lateinamerika - neuere Entwicklungen. In: Theologische Literaturzeitung; Monatsschrift für das gesamte Gebiet der Theologie und Religionswissenschaft. Jun/2017, p. 589-602.

2 LAS CASAS, Bartolomé de. Tratado sobre la materia de los indios que se han hecho esclavos. Biblioteca Virtual Universal. Disponível em: <http://www.biblioteca.org.ar/ libros/131622.pdf>, p. 17. Acesso em: 10 jan. 2018.

3 BERTOLDO, F. C. A pertinência do método evangelizador de Bartolomeu de Las Casas. IDENTIDADE!, v. 22, p. 323-326, 2017. p. 326. 
outros, como colaboração forçada, sem maiores condições de oposição; houve também resistência passiva, incluindo a radicalidade do suicídio ou do aborto; ou mesmo na hostilidade brutal dos que puderam defender seu modo de vida em luta armada. ${ }^{4}$ Mas, por mais intensas que tenham sido determinadas resistências, o golpe sobre as sociedades pré-colombianas foi fatal, e elas terminaram por ser desestruturadas "em todos os níveis: demográfico, econômico, social e ideológico".5

O núcleo central de trabalho e produção na América Central, antes da chegada dos espanhóis, era a família campesina. Essa unidade estava ligada a outras num esforço conjunto de colheita e estocagem de sementes. Como o ciclo agrícola para da produção de milho durava noventa dias úteis, sobrou energia excedente para outros empreendimentos econômicos. Então os camponeses atuavam como agricultores, caçadores, coletores, artesãos ou construtores, de forma alternada. Ou seja, não havia divisão de trabalho por especialização; apenas o tempo de sua realização o dividia. As aldeias foram submetidas a elites teocráticas e militares de fortes estados centralizados, as quais unificaram a atividade laboral em um projeto único (como no caso asteca do México ou o inca no Peru), realocando os camponeses para atividades sazonais - mas sem modificar essencialmente a economia campesina como tal. A divisão anual da força de trabalho, no caso mexicano, era chamada coatequil, uma rearticulação de trabalhadores selecionados das aldeias, cuja soma significava uma formidável força de trabalho concentrada para desempenhar tarefas gigantescas em um tempo relativamente curto, sem que as comunidades de onde esses trabalhadores saíam interrompessem suas atividades ordinárias. Desta forma, os recursos eram extraídos das camadas populares, sendo parte da produção deixada para o sustento dos trabalhadores e a reprodução das células domésticas locais. Era, portanto, uma economia baseada em um sistema unificado de concentração e redistribuição de energia de trabalho, de reciprocidade ampla e articulada. Tal coletivismo era regido com um propósito religioso, respondendo a um calendário sagrado que definia a atividade laboral. ${ }^{6}$

$4 \quad$ WACHTEL, Nathan. Los indios y la conquista española. In.: BETHELL, Leslie (Org.). Historia de América Latina: 1. América Latina colonial: La América precolombina y la conquista. Barcelona: Editorial Crítica, 1990. p. 170.

5 WACHTEL, 1990, p. 174.

6 FLORESCANO, Enrique. La transformación de la Antigua economía y la formación de los trabajadores coloniales (1500-1560). In.: Revista de la Universidad de México, México, v. 34, n. 10, jun. 1980. Disponível em: <http://www.revistadelauniversidad. unam.mx/historico/10430.pdf>. Acesso em: 17 set. 2018. 
Pois foi esse sistema econômico de reciprocidade que a invasão espanhola destruiu na chegada de Hernán Cortés ao México em 1519. $\mathrm{O}$ antigo sistema de reciprocidade do coatequil foi substituído pela arbitrariedade de uma exploração de viés único, a encomienda. Nesta, obrigava-se a entrega do tributo na forma de produtos e força de trabalho, mas em uma cobrança não mais como parte de uma grande articulação centralizada, mas localizada em cada unidade. Também não se tratava mais de uma grande economia autossustentável, mas na produção intensiva de mercadorias para a exportação. Não apenas mudou o sentido do trabalho, como a cobrança dos tributos ficou sob a arbitrariedade e ambição desmedida do encomendero, o responsável europeu pela unidade produtiva. A desestruturação social foi intensa: os calendários sagrados foram eliminados, gerando uma sensação de desamparo nas populações que já não compreendiam mais o tempo sagrado; as atividades de descobertas, aberturas de estradas e criação de novas vilas desestabilizaram o antigo espaço de vida e trabalho; e a noção de autoridade da antiga estrutura do cacicado tradicional foi substituída pelos capitães espanhóis ou pelos seus aliados indígenas, expandindo ainda mais o caos. ${ }^{7}$

Com tantas transformações, o princípio da reciprocidade entre as aldeias ruiu, bem como sua produtividade. Assim, entre 1521 e 1541, ocorreu um contínuo descenso populacional, ao mesmo tempo em que as taxas de impostos aumentaram. Mas a maior transformação do sistema ocorreu mesmo a partir de 1530, quando a extração de prata e ouro ganhou centralidade econômica, o que significou intensa escravização de indígenas e o abandono das atividades tradicionais em benefício da exploração de minas. Lorenzo Galmés descreve o quanto foi devastadora a situação das encomiendas:

Muitos encomenderos abusaram de suas vantagens e prerrogativas, maltrataram os indios e impuseram-lhes trabalhos excessivos, descuidaram de sua educação humana e formação cristã e, apesar do regulamento do tempo, lugar e condições de trabalho que as leis prescreviam, os fatos culminaram em estado de opressão que bem se poderia qualificar de escravidão indígena. [...] Especialmente desastroso foi o repartimiento de inúmeros índios em beneficio do rei e das altas personagens da corte, todos ausentes e sem nunca terem pisado o solo das indias, mas beneficiados pela exploração dos indígenas levada em frente, em seu nome, muito

7 FLORESCANO, 1980. 
frequentemente por desalmados capatazes. A ânsia de enriquecimento à custa do índio penetra as mais altas esferas do Estado. ${ }^{8}$

Foi uma catástrofe. Alguns pesquisadores estimam que a população inicial do México Central, em torno de 25 milhões de habitantes em 1519 , caiu até cerca de 2,6 milhões em 1568. Outros elaboram números mais modestos, acreditando que a queda foi de aproximadamente 11,5 milhões para pouco mais de um milhão em apenas um século. Seja como for, tratou-se de um desastre demográfico excepcional. ${ }^{9}$

Tal desastre foi o resultado prático de uma teoria preconcebida, na qual um dominador submete seres que considera inferiores. Segundo Nildo Ouriques, os ibéricos perceberam o encontro com os ameríndios como um encontro de civilizados e bárbaros.10 Foi mais do que um disputa pela terra ou riquezas, mas de identidades. Por isso, Heinz Steffan afirma que o processo de dominação física é sempre seguida por outra ideológica:

A destruição da identidade deste [do submetido] é a conditio sine qua non de um sistema estável de dominação. A colonização físico-material requer a colonização mental para que possa realizar o fim último de qualquer sistema de dominação: a exploração perene do submetido. [...] o volume do terror fisico pode diminuir, já que sua função é assumida, em grande parte, por mecanismos de doutrinação ideológica. Dito de outra forma: conseguida a alienação do submetido mediante (principalmente) a coerção fisica, a tarefa do colonizador se concretiza ao manter este estado de alienação e ao convertê-lo em seu estado natural [...]. ${ }^{11}$

Os invasores espanhóis tentavam fazer com que os povos nativos passassem da rejeição à invasão para uma aceitação da presença dos espanhóis em suas terras. Para isso, se utilizaram da religião. No entanto, os índios eram voltados às suas crenças e aos seus deuses. Além disso, era

8 GALMÉS, Lorenzo. Bartolomeu de Las Casas. Defensor dos direitos humanos. São Paulo: Paulinas, 1991. p. 13.

9 CARAVAGLIA \& MARCHENA, Juan. América Latina de los orígenes a la independencia. Vol. 1. Barcelona: Crítica, 2005. p. 143.

10 OURIQUES, Nildo Domingos. O Significado da Conquista: cinco séculos de domínio. In: RAMPINELLI, Waldir José; OURIQUES, Nildo Domingos (Orgs.). Os 500 Anos: a conquista interminável. Petrópolis: Vozes, 1999. p. 90.

11 STEFFAN, Heinz Dieterich. Sociedade Global - Identidade Colonial. In: RAMPINELLI, Waldir José; OURIQUES, Nildo Domingos. (Org). Os 500 Anos: a conquista interminável. Petrópolis: Vozes, 1999. p. 73. 
difícil compreender o cristianismo e a contradição da pregação do Jesus crucificado com a ganância de seus seguidores. Estava estabelecido um choque de culturas que não podia passar simplesmente pela assimilação ou resistência totais.

É por isso que o processo de desintegração da sociedade nativa não significou sua completa destruição. Permaneceram remanescentes, naquilo que Gruzinski chamou de "mestiçagem" entre a Europa cristã e a Mesoamérica pagã recém-conquistada. ${ }^{12}$ As mestiçagens ocorrem em "leitos de identidades quebradas. Se nem todas as mestiçagens nascem necessariamente de uma conquista, as desencadeadas pela expansão colonial na América iniciam-se invariavelmente sobre os escombros de uma derrota". ${ }^{13} \mathrm{O}$ mestiço surgiu do estupro das índias, das concubinagens e dos raros casamentos entre elas e os conquistadores, um elemento perturbador da ordem e à margem da oficialidade. Com o tempo, coube aos índios, negros, espanhóis e mestiços inventarem novos meios de conviver, improvisando em todos os níveis possíveis. Foi sobre esse quadro de intensa amálgama cultural e étnica que se impôs o processo de ocidentalização. ${ }^{14}$ As autoridades civis e eclesiásticas se esforçaram para "ocidentalizar" as culturas ameríndias, ou seja, tornar cristãos os nativos da América. Esse foi o processo que tentou introduzir na América a sociedade renascentista europeia, especialmente aquela desenvolvida sob a coroa de Castela. ${ }^{15}$

Durante um século, "a ocidentalização instaurou novas referências materiais, políticas, institucionais e religiosas destinadas a controlar os distúrbios introduzidos pela Conquista". ${ }^{16}$ Essa ocidentalização se deu especialmente pela réplica, no Novo Mundo, das instituições oriundas do Velho: a tipologia das cidades, portos, estradas, criação de universidades e construção de igrejas. As instituições públicas também reproduziram as da metrópole, com os cabildos comandando novos municípios, língua uniformizando administrações, decretos legais aplicados a todo o Império Espanhol. Nos centros das cidades eram erguidos os símbolos do

12 GRUZINSKI, Serge. O pensamento mestiço. São Paulo: Companhia das Letras, 2001. p. 62.

13 GRUZINSKI, 2001, p. 64.

14 GRUZINSKI, 2001, p. 78.

15 GRUZINSKI, 2001, p. 93.

16 GRUZINSKI, 2001, p. 94. 
poder invasor: igrejas, prefeitura, fonte - ostentando o triunfo espanhol e católico. ${ }^{17}$

Nesse contexto colonialista, era imprescindível que os nativos abandonassem suas crenças e subscrevessem a fé cristã para integrarem o Império. A fé era o único denominador comum aos mais diversos povos sob o controle do rei espanhol, razão pela qual a religião tornou-se questão política vital. As estratégias de conversão dos indígenas foram inúmeras. Primeiro, a construção da igreja, com sua imensa abóbada, que os deixava estupefatos e marcava fisicamente o poder técnico dos invasores; segundo, a multiplicação de mosteiros com suas escolas, a partir dos primeiros franciscanos, que educaram os filhos da nobreza indígena e os cooptaram para o empreendimento colonialista; e terceiro, a conquista dos corpos, submetendo família e casamento às normas da igreja. ${ }^{18}$

O aspecto ideológico, ou religioso, portanto, estava intrinsicamente relacionado ao poderio espanhol e à sua estratégia de dominação dos povos conquistados. E foi também do contexto dos religiosos, de dentro da própria Igreja que dava suporte ao Império, que vieram os movimentos de oposição ao regime, incluindo Bartolomeu de Las Casas.

\section{A Conquista da América Hispânica e o Frei Bartolomeu de Las Casas}

Las Casas nasceu em Sevilha, Espanha, possivelmente no dia 11 de novembro de 1484, filho de Pedro de Las Casas e Isabel de Sora. Teve quatro irmãs: Isabel, Inez, Catarina e Marina. Sua primeira formação se deu na Escola Catedral de Sevilha, onde dois de seus tios eram professores. ${ }^{19}$ No dia 13 de fevereiro de 1502, com 18 anos de idade, Las Casas partiu para a América, juntamente com seu pai e doze missionários, desembarcando na Ilha Espanhola (Santo Domingo, Haiti). Las Casas ficou impressionado com a acolhida dos nativos.

Nos anos seguintes, Las Casas exerceu a função de encomendero e doutrinador, integrado (ao que parece) ao regime colonial até pelo menos 1510. Naquele ano, os dominicanos chegaram a Santo Domingo e ficaram

\footnotetext{
17 GRUZINSKI, 2001, p. 94-96.

18 GRUZINSKI, 201, p. 97-100.

19 JOSAPHAT, Frei Carlos. Las Casas: Todos os direitos para todos. São Paulo: Loyola, 2000. p. 43.
} 
horrorizados com a situação dos nativos escravizados pelos encomenderos, denunciando a situação por meio da pregação do frei Antônio de Montesinos, no Advento de 1511. Baseado no texto de Lucas $3,4-8,{ }^{20}$ o sermão de Montesinos atualizava o discurso do evangelho anunciando aos espanhóis, que morreriam por causa de seu pecado mortal contra os inocentes indígenas. $\mathrm{O}$ frei interrogava sobre as razões para tanta maldade, ao invés de oferecerem a pregação da doutrina e da prática cristã. Era um discurso de denúncia e acusação, atrelado à ideia de que o índio era dócil e vítima da ganância espanhola, além de conter um germe do princípio de igualdade entre os homens. Las Casas ficou profundamente impactado pela prédica. ${ }^{21}$ Dali em diante, passou a atuar em favor dos nativos.

Em 1511 aconteceu o primeiro protesto de Las Casas contra a encomienda. Os espanhóis mostravam-se cada vez mais desumanos no tratamento dado aos índios, e Las Casas argumentou sobre uma alternativa para o império, sem necessariamente rejeitar os princípios centrais do imperialismo. ${ }^{22} \mathrm{Em} 1513$, Las Casas assumiu uma nova missão como capelão militar em Cuba, incumbido de catequizar os índios e instruir os militares com formação cristã. Ali, assumiu definitivamente a defesa dos direitos dos indígenas, combatendo a imposição conquistadora espanhola, uma vez que "a invasão espanhola no continente americano transformou-se em trágico destino dos nativos". ${ }^{23}$

Bartolomeu de Las Casas radicalizou sua oposição ao sistema ao abdicar de sua encomienda em 1514. Voltou para a Espanha em 1515 a fim de propor uma reforma do sistema de colonização na América, iniciando a batalha pessoal a favor de um modelo de conversão pacífica dos índios. Permaneceu na Espanha de 1517 a 1519. Finalmente, tentou realizar, na prática, a colonização pacífica em Porto Rico em 1520 e 1521 , o que resultou em fracasso. ${ }^{24}$

20 "Voz do que clama no deserto: preparai o caminho do Senhor, tornai reta suas veredas; [...] Raça de víboras! Quem vos ensinou a fugir da ira que está para vir? Produzi, então, frutos dignos de arrependimento."

21 FREITAS NETO, José Alves de. Bartolomé de Las Casas: a narrativa trágica, o amor cristao e a memória americana. São Paulo: Annablume, 2003. p. 37-40.

22 RIEGER, Joerg. Cristo e Império de Paulo aos Tempos Pós-coloniais. São Paulo: Paulus, 2009. p.113.

23 HOFFNER, Joseph. Colonialismo e Evangelho, Ética do Colonialismo do Século de Ouro. Rio de Janeiro: Editora da USP, 1973. p. 175.

24 FREITAS NETO, 2003, p. 41-47. 
Em 1524, Las Casas foi nomeado pelo rei como "Procurador dos Índios" e realizou a sua profissão religiosa na Ordem dos Dominicanos. "Foi o primeiro presbítero ordenado no Novo Mundo. Uma nova fase e grave responsabilidade nascia na agitada vida de Las Casas e, com ela, maiores exigências humanas e cristãs". ${ }^{25}$ Entre 1521 e 1540, Las Casas atuou na ordem dominicana com ensino e missões em diversas localidades da América, época em que escreveu obras como História das Índias, Apologética histórica das Índias e o tratado Único modo de atrair todos os povos à verdadeira religião, dentro do princípio da evangelização pacífica. ${ }^{26}$

Na última obra citada, Único modo de atrair todos os povos à verdadeira religião (1537), Las Casas traçou a seguinte pergunta fundamental: "Como anunciar o Evangelho, na forma e do jeito que convêm à elevação dessa mensagem e à dignidade do ser humano a que se destina?". ${ }^{27}$ Para ele, o modo de encaminhar as pessoas à verdadeira religião deve ser delicado e persuasivo. "O modo de mover e dirigir, de atrair e conduzir a criatura racional ao bem, à verdade, à virtude, à justiça, à fé autêntica e à verdadeira religião deve ser conforme ao modo, à natureza e à condição dessa criatura racional". ${ }^{28}$ Seu modo de converter respeita a dignidade e a cultura dos nativos. "A fé implica assentimento da inteligência ao que se crê. Assentir é o que propriamente se denomina crer. Ora, segundo Santo Agostinho, crer é pensar com assentimento". ${ }^{29}$

Bartolomeu defendia que, para crer, era preciso que acontecesse o processo de persuasão pela razão. A Sagrada Escritura ajuda a compreender este processo de persuasão: "Tendo o pensamento do Senhor, tratamos de persuadir os homens" (1Co 2,16), e "Entrando na sinagoga e durante três meses falava com confiança, discutindo sobre o Reino de Deus e tentando convencê-los" (At 19,8). "Logo, o modo de instruir os homens na reta fé e na verdadeira religião deve persuadir o entendimento e atrair, estimular e exortar a vontade". ${ }^{30}$ Por isso, segundo Las Casas, o modo da pedagogia missionária de Jesus Cristo teve caráter suave e pacífico: "quando enviou

\footnotetext{
25 GALMÉS, 1991, p. 34.

26 FREITAS NETO, 2003, p. 47-48.

27 LAS CASAS, Bartolomeu de. Único modo de atrair todos os povos à verdadeira religião. Obras completas I. São Paulo: Paulus, 2005. p. 33. 
os santos apóstolos e discípulos para pregar aos judeus, enviando-os como a um estádio, a fim de que pouco a pouco se preparassem e exercessem para a futura luta com todo o orbe da terra, que iam enfrentar". ${ }^{31}$

A obra Único modo de atrair todos os povos à verdadeira religião fez uso de uma decisão fundamental vinda diretamente de Roma, a qual Las Casas usou e comentou com entusiasmo. ${ }^{32} \mathrm{O}$ papa Paulo III promulgou a bula Sublimis Deus em 9 de junho de 1537, a qual viria a ser considerada a primeira declaração universal dos direitos humanos. A Carta Magna afirmou: "Nós, ainda que indignos, exercemos na terra o poder de Nosso Senhor. Consideramos que os índios são verdadeiros homens". O Papa Paulo III afirmava que os índios "não somente são capazes de entender a fé católica, de acordo com nossas informações, acham-se desejosos de recebê-la", de acordo com a bula Sublimis Deus.

Em 1540, Las Casas retornou à Espanha, onde encontrou ambiente favorável às suas ideias, publicando em 1542 o texto Brevíssima relação da Destruição das Índias (ou Paraíso Destruído). ${ }^{33}$ Esse texto causou consternação, dada a crueza dos detalhes da sua narrativa:

Os espanhóis, com seus cavalos, suas espadas e lanças começaram a praticar crueldades estranhas; entravam nas vilas, burgos e aldeias, não poupando nem as crianças e os homens velhos, nem as mulheres grávidas e parturientes e lhes abriam o ventre e as faziam em pedaços como se estivessem golpeando cordeiros fechados em seu redil. Faziam apostas sobre quem, de um só golpe de espada, fenderia e abriria um homem pela metade, ou quem, mais habilmente e mais destramente, de um só golpe lhe cortaria a cabeça, ou ainda sobre quem abriria melhor as entranhas de um homem de um só golpe. ${ }^{34}$

Las Casas alcançou o efeito esperado. No mesmo ano, o rei Carlos $\mathrm{V}$ editou as Leis Novas, proibindo novas encomiendas e a servidão indígena. A reação nas colônias foi imediata: o frei foi visto como o responsável pela legislação, contrária aos interesses dos colonizadores. Ainda no ano de 1542, Bartolomeu de Las Casas foi nomeado bispo de Chiapas, no México, onde tomou medidas contra os encomenderos, pregando contra

31 LAS CASAS, 2005, p. 139.

32 JOSAPHAT, 2000, p. 105.

33 FREITAS NETO, 2003, p. 49.

34 LAS CASAS, Bartolomeu de. Brevísima relación de La destrucción de las Indias. Barcelona: Orbis, 1986. p. 33. 
suas ações, negando-lhes o sacramento e a confissão. ${ }^{35}$ Em 1547, Las Casas renunciou à sua diocese e voltou para a Espanha, onde permaneceu até sua morte em $1566 .{ }^{36}$ Foi neste período que ele entrou em discussão com Juan Ginés de Sepúlveda, debate que trataremos a seguir.

\section{Questões Contraditórias sobre o Direito da Guerra no Processo de Colonização entre Las Casas e Sepúlveda}

Las Casas era um autodidata. Grande parte de seu conhecimento teórico foi adquirido durante o retiro de dez anos no convento dominicano em Santo Domingo e também ao longo de sua vida, incentivado pelo debate e pela polêmica.

Assim, ao enfrentar Sepúlveda, que era um grande filósofo e historiador, conhecedor de Aristóteles, Las Casas, que nunca frequentou bancos universitários, viu-se diante da necessidade de estudar a fundo a obra aristotélica. Adquiriu um amplo conhecimento, principalmente de suas obras ético-políticas, e passou a utilizar o pensamento do filósofo grego na defesa da causa indígena. Las Casas entendia que os príncipes cristãos e a Igreja não têm jurisdição para impor um castigo aos índios pelos crimes cometidos contra a lei natural. A partir da lei natural de Santo Tomás de Aquino, Las Casas afirma a existência de um direito natural à liberdade inerente a todo ser humano.

O humanista Juan Ginés de Sepúlveda (1490-1573) afirma que "o bispo Las Casas nega o poder real e atual de Jesus Cristo sobre o todo o criado, defende a idolatria, concorda com os sacrifícios humanos e falsos deuses, nega o dever da moral objetiva" ${ }^{37}$, se tratando de questões levantadas no debate entre ambos realizado na cidade de Valladolid, Espanha, em 1550 e 1551.

A questão se dava em torno das perguntas: "Os índios são seres livres ou escravos naturais?"; "Os índios têm alma?" Las Casas busca assegurar a identidade e a dignidade dos índios americanos, enquanto Sepúlveda defende a condição dos índios como não humanos, isto é, de animais, visando legitimar a escravização, a conquista e a colonização espanholas que

35 FREITAS NETO, 2003, p. 50.

36 FREITAS NETO, 2003, p. 52.

37 GALMÉS, 1991, p. 242-243. 
estavam acontecendo no Novo Mundo. Las Casas consegue uma grande vitória contra Sepúlveda, quando, ao saber da obra Demócrates Segundo ou das Justas Causas da Guerra contra os Índios, de Sepúlveda, que era extremamente lesiva à causa indígena, consegue evitar a sua publicação.

Sepúlveda defendia que os índios eram seres inferiores e de costumes bárbaros. Entendia que o índio devia se submeter ao povo espanhol, de costumes mais civilizados e mais cristãos, portanto, seres de cultura superior. Ele entendia que a guerra contra os índios se justifica como castigo pelos crimes que eles cometem contra a lei natural com sua idolatria e sacrifícios de vítimas humanas aos deuses.

Caso os índios se recusassem a serem submetidos ao domínio espanhol, era justificada a guerra contra eles para forçá-los à submissão. Ele ressalta que os infiéis não podem ser castigados somente por sua infidelidade, ou seja, por não serem cristãos. Concretamente, isso significava que a punição é a prática de idolatria ou de outros pecados contra a lei natural, os quais a Igreja está obrigada a combater. De acordo com Sepúlveda: “O Papa tem, pois, poder sobre todas as nações não somente para predicar o Evangelho, mas também para obrigar aos povos, se lhes for possível, a observar a lei natural a qual todos os homens estão submetidos". ${ }^{38}$ Em meio a este debate, o Imperador Carlos V convocou 14 teólogos de renome na época, que se reuniram em Valladolid, em 1550 e 1551, para decidir sobre a questão referente ao processo de conquista: era justa a guerra movida contra os índios com o fim de submetê-los ao cristianismo?

Sepúlveda invocava São Tomás para justificar esta tese, para quem seria lícito fazer guerras aos pagãos que ofendessem a fé cristã com blasfêmias e idolatrias (S. Th. 2.2q.949.3 ad 2). Sepúlveda entendia que o "direito natural deve ser restringido àquilo que seja a opinião dos homens doutos, de tal maneira que compete aos povos de superioridade natural e ética determinar aquilo que seja justo por natureza". ${ }^{39}$ Entende que seria necessário que os índios se submetessem ao império dos seres humanos civilizados e cristãos autênticos, no caso, os espanhóis. Afirmava ainda que declarar guerra contra os infiéis seria um meio para abrir caminho ao processo de evangelização através da pregação do Evangelho.

38 SEPÚLVEDA, 1941, p. 63.

39 GARCIA-PELAYO. Introducción. In: SEPÚLVEDA, Juan Ginés de. Tratado sobre las justas causas de la guerra contra los indios. México: Fondo de Cultura Economica, 1941. p. 9. 
Las Casas rebate esta posição de Sepúlveda, afirmando que os índios estão sob a proteção da Igreja: “Tais pessoas pertencem potencialmente à Igreja; portanto, estão sob sua proteção; deste modo corresponde à Igreja e ao Papa, que é sua cabeça, velar para que obtenham a salvação". ${ }^{40}$

Las Casas afirmava que os sacrifícios de pessoas, segundo a tradição indígena, faziam menos vítimas do que a guerra, por isso é um princípio aceitável, como um mal menor, Assim,

Se se encontram infiéis que cometem tal classe de crime, isto é, sacrificam crianças para oferecê-las aos deuses ou para comê-las, mesmo que à Igreja corresponda pôr remédio para suprimir este mal, nem sempre se lhes deve fazer a guerra, mas se deve ponderar muito essa questão, pois não devemos declará-la para impedir a morte de uns tantos inocentes se com isso sacrificarmos uma multidão de homens sem que eles mereçam, nem se com isso destruirmos reinos inteiros e incutirmos nas almas daqueles o ódio à Religião Cristã de maneira que para sempre se neguem a ouvir o nome de Cristo ou sua doutrina, o que seria certamente contrário ao fim a que pretende Deus e a Igreja. ${ }^{41}$

Em defesa aos sacrifícios humanos relacionados aos deuses que os povos indígenas adoravam, Las Casas escreve que "a opinião que os índios têm sobre seus deuses, sobre os sacrifícios que devem oferecer e sobre as coisas que devem ser sacrificadas, estão comprovadas pelo consenso geral de todos os povos conhecidos nas índias". ${ }^{42}$ Já fazer guerra para abrir caminho à pregação do Evangelho é um ato contrário ao próprio Evangelho, afirmava Las Casas.

Sepúlveda tinha uma visão somente da cátedra ${ }^{43}$, diferentemente de Las Casas que conviveu com os índios e conhecia sua cultura. Las Casas refletia a partir da realidade da terra, da natureza, da água para demonstrar que seus habitantes eram saudáveis, racionais e viviam em harmonia entre si e com a natureza.

$40 \quad$ LAS CASAS, 1975, p. 248.

41 LAS CASAS, 1975, p. 251.

42 LAS CASAS, 1975, p. 276.

43 "Existem outras causas de guerra justa menos frequentes, mas nem por isso menos justas, fundadas no direito natural e divino; e uma delas é a permissão para submeter com armas, se outro caminho não for possível, aqueles que por condição natural devem obedecer a outros, mas se recusam a fazê-lo. Os grandes filósofos declaram que esta guerra é justa por lei da natureza." (SEPÚLVEDA, 1941, p. 81). 
Las Casas descreveu a vida moral, as virtudes e qualidades dos povos indígenas, no âmbito familiar e social. Engajou-se pela paz, justiça e palavra em vez da espada ou da coação. Nele há uma defesa ardente dos índios como seres humanos, considerados até mais cristãos que os conquistadores, uma vez que, tinham costumes que valorizavam o coletivo e não somente o individual. Segundo Las Casas,

Os índios são nossos irmãos, pelos quais Cristo deu sua vida. Por que os perseguimos sem que tenham merecido tal coisa, com desumana crueldade? O passado, e o que deixou de ser feito, não tem remédio; seja atribuído à nossa fraqueza sempre que for feita a restituição dos bens impiamente arrebatados [...]. Sejam enviados aos índios pregoeiros integros, cujos costumes sejam espelho de Jesus Cristo e cujas almas sejam reflexos das de Pedro e Paulo. Se for feito assim, estou convencido de que eles abraçarão a doutrina evangélica, pois não são néscios nem bárbaros, mas de inata sinceridade, simples, modestos, mansos e, finalmente, tais que estou certo que não existe outra gente mais disposta do que eles a abraçar o Evangelho, o que, uma vez por eles recebido, é admirável com que piedade, ardor, fé e caridade cumprem os preceitos de Cristo e veneram os sacramentos". ${ }^{4}$

Podemos afirmar que a teoria da escravidão natural se tornou o tema central da discussão sobre a política colonial espanhola: "Debaixo do manto de autoridade indiscutível de Aristóteles era encontrada uma solução simples que tinha um grande poder de convencimento e fornecia uma base teórica para a resolução jurídica". ${ }^{45}$

\section{Conclusão}

Bartolomeu de Las Casas tornou-se destacado defensor dos povos indígenas. Segundo ele, a Igreja deve exercer a sua jurisdição a fim de promover a salvação das almas de todos os seres humanos. Defendia que os sacrifícios humanos de povos indígenas seriam práticas aceitáveis, portanto, não deviam ser reprimidas e combatidas. Afirmava que os infiéis que nunca professaram a fé cristã não podiam ser compelidos pelo Papa a aceitá-la, mas deviam ser exortados de forma pacífica e,

44 LAS CASAS, 1550 apud SUESS, Paulo (Org.). A conquista espiritual da América espanhola. Petrópolis: Vozes, 1992. p. 543.

45 TOSI, Giuseppe. Aristóteles e a escravidão natural. Boletim do CPA, Campinas, n. 15. p. 71-100, jan./jun. 2003. p. 51. 
caso aceitassem a fé cristã e fossem batizados, passariam a pertencer ao rebanho de Cristo e se tornariam súditos da Igreja, submetendo-se à sua jurisdição. Por esta razão, a guerra não se justificaria na percepção de Bartolomeu de Las Casas.

Diferentemente, Sepúlveda destacava alguns aspectos do comportamento indígena como provas para justificar o direito da guerra: a prática de sacrifícios humanos, canibalismo e idolatria. A guerra contra os índios seria justificada como meio para abrir caminho para a implantação e difusão do cristianismo, ou seja, tinha função de retirar os obstáculos para a implantação do cristianismo. Sepúlveda reconheceu na teoria da escravidão natural, defendida por Aristóteles, um argumento forte para defender os espanhóis e justificar o uso da força para submeter os índios ao domínio da "superioridade cultural espanhola".

Em síntese, Las Casas afirmava que seria necessário garantir a proteção dos indígenas por terem verdadeiros direitos. Quando os espanhóis vieram colonizar os povos indígenas, tal liberdade teria sido ferida. Bartolomeu de Las Casas tinha a convicção de que o único modo de atrair e converter os índios ao cristianismo era através da persuasão, sem o uso da violência. A guerra não se justifica.

\section{Referências}

BERTOLDO, F. C.. A pertinência do método evangelizador de Bartolomeu de Las Casas. Identidade!, v. 22, p. 323-326, 2017.

BRUGNERA, Nedilson Lauro. A escravidão em Aristóteles. Porto Alegre: EDIPUCRS, 1998.

CARAVAGLIA \& MARCHENA, Juan. América Latina de los orígenes a la independencia. Vol. 1. Barcelona: Crítica, 2005.

FLORESCANO, Enrique. La transformación de la Antigua economía y la formación de los trabajadores coloniales (1500-1560). In.: Revista de la Universidad de México, México, v. 34, n. 10, jun. 1980. Disponível em: $<$ http://www.revistadelauniversidad.unam.mx/historico/10430.pdf $>$. Acesso em: 17 set. 2018.

FREITAS NETO, José Alves de. Bartolomé de Las Casas: a narrativa trágica, o amor cristao e a memória americana. São Paulo: Annablume, 2003. GALMÉS, Lorenzo. Bartolomeu de Las Casas. Defensor dos direitos humanos. São Paulo: Paulinas, 1991. 
GARCIA-PELAYO. Introducción. In: SEPÚLVEDA, Juan Ginés de. Tratado sobre las justas causas de la guerra contra los indios. México: Fondo de Cultura Economica, 1941.

HOFFNER, Joseph. Colonialismo e Evangelho, Ética do Colonialismo do Século de Ouro. Rio de Janeiro: Editora da USP, 1973.

JOSAPHAT, Frei Carlos. Las Casas: todos os direitos para todos. São Paulo: Loyola, 2000.

LAS CASAS, Bartolomeu de. Único modo de atrair todos os povos à verdadeira religião. Obras completas I. São Paulo: Paulus, 2005.

LAS CASAS, Bartolomeu de. Brevísima relación de La destrucción de las Indias. Barcelona: Orbis, 1986.

LAS CASAS, Bartolomeu de. Tratado sobre la materia de los indios que se han hecho esclavos. Biblioteca Virtual Universal. Disponível em: <http://www.biblioteca.org.ar/libros/131622.pdf>. Acesso em: 10 jan. 2018.

OURIQUES, Nildo Domingos. O Significado da Conquista: cinco séculos de domínio. In: RAMPINELLI, Waldir José; OURIQUES, Nildo Domingos (Orgs.). Os 500 Anos: a conquista interminável. Petrópolis: Vozes, 1999. p. 83-109.

RIEGER, Joerg. Cristo e Império de Paulo aos Tempos Pós-coloniais. São Paulo: Paulus, 2009.

SINNER, Rudolf von. Theologie in Lateinamerika - neuere Entwicklungen. In: Theologische Literaturzeitung; Monatsschrift für das gesamte Gebiet der Theologie und Religionswissenschaft. Jun/2017, p. 589-602.

STEFFAN, Heinz Dieterich. Sociedade Global - Identidade Colonial. p. 69-82. In: RAMPINELLI, Waldir José; OURIQUES, Nildo Domingos. (Org). Os 500 Anos: a conquista interminável. Petrópolis: Vozes, 1999.

SUESS, Paulo (Org.). A conquista espiritual da América espanhola. Petrópolis: Vozes, 1992.

TOSI, Giuseppe. Aristóteles e a escravidão natural. Boletim do CPA, Campinas, n. 15. p. 71-100, jan./jun. 2003.

WACHTEL, Nathan. Los indios y la conquista española. In.: BETHELL, Leslie (Org.). Historia de América Latina: 1. América Latina colonial: La América precolombina y la conquista. Barcelona: Editorial Crítica, 1990. 